\title{
Increased hepatic secretion of very-low-density lipoprotein apolipoprotein B-100 in NIDDM
}

\author{
M.H. Cummings ${ }^{1}$, G.F. Watts ${ }^{2}$, A.M. Umpleby ${ }^{1}$, T. R. Hennessy ${ }^{1}$, R.Naoumova ${ }^{3}$, B. M. Slavin ${ }^{4}$, G.R. Thompson ${ }^{3}$, \\ P.H. Sönksen \\ ${ }^{1}$ Department of Medicine, St. Thomas' Hospital, United Medical and Dental School of Guys and St. Thomas', London, UK \\ ${ }^{2}$ University Department of Medicine, University of Western Australia, Perth, Australia \\ ${ }^{3}$ Lipoprotein Team, MRC Clinical Sciences Centre, Hammersmith Hospital, London, UK \\ ${ }^{4}$ Department of Chemical Pathology, St. Thomas' Hospital, United Medical and Dental School of Guys and St. Thomas', \\ London, UK
}

Summary We measured the hepatic secretion of very-low-density lipoprotein apolipoprotein B-100 (VLDL apoB) using a stable isotope gas-chromatography mass-spectrometry method in six patients with non-insulin-dependent diabetes mellitus (NIDDM) (four males, two females, age $57.5 \pm 2.2$ years (mean \pm SEM), weight $88.2 \pm 5.5 \mathrm{~kg}$, glycated haemoglobin $\left(\mathrm{HbA}_{1}\right) 8.5 \pm 0.5 \%$, plasma total cholesterol concentration $5.7 \pm 0.5 \mathrm{mmol} / 1$, triglyceride $3.8 \pm 0.9$ $\mathrm{mmol} / \mathrm{l}$, high-density lipoprotein (HDL) cholesterol $1.0 \pm 0.1 \mathrm{mmol} / \mathrm{l}$ ) and six non-diabetic subjects matched for age, sex and weight (four males, two females, age $55.7 \pm 2.8$ years, weight $85.8 \pm 5.6 \mathrm{~kg}$, $\mathrm{HbA}_{1} 6.5 \pm 0.1 \%$, plasma total cholesterol concentration $5.7 \pm 0.5 \mathrm{mmol} / 1$, triglyceride $1.2 \pm 0.1 \mathrm{mmol} / 1$, $\mathrm{HDL}$ cholesterol $1.4 \pm 0.1 \mathrm{mmol} / \mathrm{l})$. $\mathrm{HbA}_{1}$, plasma triglyceride and mevalonic acid (an index of cholesterol synthesis in vivo) concentrations were significantly higher in the diabetic patients than in the non-diabetic subjects $(p=0.006, p=0.02$ and $p=0.004$, respectively). VLDL apoB absolute secretion rate was significantly higher in the diabetic patients compared with the non-diabetic subjects $(2297 \pm 491$ vs $921 \pm 115 \mathrm{mg} /$ day, $p<0.05$ ), but there was no signifi- cant difference in the fractional catabolic rate of VLDL apoB. There was a positive correlation between VLDL apoB secretion rate and (i) fasting Cpeptide $(r=0.84, p=0.04)$ and (ii) mevalonic acid concentration $(r=0.83, p<0.05)$ in the diabetic patients but not in the non-diabetic subjects. There was also a significant positive association between plasma mevalonic acid and plasma C-peptide $(r=0.82$, $p<0.05$ ) concentrations in the diabetic patients. We conclude that in NIDDM, there is increased hepatic secretion of VLDL apoB which may partly explain the dyslipoproteinaemia seen in this condition. We suggest that increased secretion of this apolipoprotein may be a consequence of resistance to the inhibitory effect of insulin on VLDL apoB secretion. Insulin resistance may also be the mechanism by which cholesterol synthesis, a regulator of apoB secretion, is increased in NIDDM. [Diabetologia (1995) 38: 959-967]

Key words Very-low-density lipoprotein apolipoprotein B-100, non-insulin-dependent diabetes mellitus, stable isotopes, gas-chromatography mass-spectrometry, mevalonic acid.
Received: 20 September 1994 and in revised form: 20 February 1995

Corresponding author: Dr. M. Cummings, Department of Medicine, North Wing, St. Thomas' Hospital, Lambeth Palace Road, London SE1 7EH, UK

Abbreviations: ApoB, Apolipoprotein B-100; VLDL, verylow-density lipoprotein; GCMS, gas-chromatography massspectrometry; MVA, mevalonic acid; Hep G2, hepatoma G2; $\alpha$-KIC, $\alpha$-ketoisocaproic acid; TC, total cholesterol; TG, triglyceride; NEFA, non-esterified fatty acids; FSR, fractional secretion rate; ASR, absolute secretion rate; $\mathrm{m} / \mathrm{z}$, mass to charge ratio; $\mathrm{CV}$, coefficient of variation.
Non-insulin-dependent diabetes mellitus (NIDDM) is associated with an increased risk of macrovascular disease [1] which may be due to abnormalities in lipid and lipoprotein metabolism [2]. The mechanism underlying diabetic dyslipoproteinaemia is not, however, fully established but may be closely linked with hyperinsulinaemia [3]. Previously, increased circulating insulin was assumed to act directly on the liver stimulating very-low-density lipoprotein (VLDL) secretion in NIDDM and contributing to hypertriglyceridaemia [4]. This concept was supported 
Table 1. Characteristics of the six diabetic and six non-diabetic subjects

\begin{tabular}{|c|c|c|c|c|c|c|c|}
\hline $\begin{array}{l}\text { Subject } \\
\text { number }\end{array}$ & $\begin{array}{l}\text { Age } \\
\text { (years) }\end{array}$ & Sex & $\begin{array}{l}\text { Weight } \\
\text { (kg) }\end{array}$ & $\begin{array}{l}\text { Body mass } \\
\text { index } \\
\left(\mathrm{kg} / \mathrm{m}^{2}\right)\end{array}$ & $\begin{array}{l}\text { Fasting } \\
\text { glucose } \\
(\mathrm{mmol} / \mathrm{l})\end{array}$ & $\begin{array}{l}\mathrm{HbA}_{1} \\
(\%)\end{array}$ & $\begin{array}{l}\text { Apo E } \\
\text { phenotype }\end{array}$ \\
\hline \multicolumn{8}{|c|}{ Diabetic patients } \\
\hline 1 & 56 & $\mathrm{M}$ & 103 & 33.7 & 7.0 & 7.0 & E3E3 \\
\hline 2 & 66 & $\mathrm{M}$ & 79 & 23.3 & 9.4 & 8.0 & E3E3 \\
\hline 3 & 55 & M & 85 & 27.1 & 8.7 & 8.9 & E3E4 \\
\hline 4 & 53 & $\mathrm{~F}$ & 88 & 34.4 & 7.4 & 7.7 & $\mathrm{E} 2 \mathrm{E} 3$ \\
\hline 5 & 53 & $\mathrm{~F}$ & 70 & 28.0 & 10.7 & 8.5 & E2E3 \\
\hline 6 & 62 & $\mathrm{M}$ & 104 & 28.8 & 12.9 & 10.4 & E2E3 \\
\hline $\begin{array}{l}\text { Mean } \\
\text { (SEM) }\end{array}$ & $\begin{array}{l}57.5 \\
(2.2)\end{array}$ & & $\begin{array}{l}88.2 \\
(5.5)\end{array}$ & $\begin{array}{l}29.2 \\
(1.7)\end{array}$ & $\begin{array}{c}9.4 \\
(0.9)\end{array}$ & $\begin{array}{c}8.5 \\
(0.5)\end{array}$ & \\
\hline \multicolumn{8}{|c|}{ Non-diabetic subjects } \\
\hline 1 & 52 & M & 104 & 33.2 & 5.0 & 6.2 & E3E3 \\
\hline 2 & 64 & $\mathrm{M}$ & 79 & 26.4 & 5.1 & 6.7 & E3E3 \\
\hline 3 & 51 & $\mathrm{M}$ & 82 & 27.7 & 5.5 & 6.2 & E2E3 \\
\hline 4 & 50 & $\mathrm{~F}$ & 84 & 30.9 & 5.6 & 6.1 & E3E3 \\
\hline 5 & 52 & $F$ & 67 & 25.2 & 5.4 & 7.0 & E3E3 \\
\hline 6 & 65 & $\mathrm{M}$ & 99 & 28.9 & 5.4 & 6.9 & E3E3 \\
\hline Mean & 55.7 & & 85.8 & 28.7 & 5.3 & 6.5 & \\
\hline (SEM) & $(2.8)$ & & (5.6) & $(1.2)$ & $(0.1)$ & $(0.1)$ & \\
\hline$p$-value & 0.15 & & 0.58 & 0.63 & 0.006 & 0.006 & \\
\hline
\end{tabular}

$\mathrm{HbA}_{1}$, glycated haemoglobin; $\mathrm{M}$, male; $\mathrm{F}$, female

by in vivo work showing a significant positive correlation between hyperinsulinaemia and enhanced secretion of VLDL by the liver in diabetes [5]. More recently, insulin administration to human subjects has been shown to decrease VLDL secretion $[6,7]$ and has led to the hypothesis that in NIDDM, there is loss of sensitivity to the normal insulin-mediated suppression of VLDL secretion $[8,9,10]$. Studies examining the metabolism of apoB, the structural protein of VLDL and a determinant of plasma lipid and lipoprotein concentrations [9], have also supported the proposed inhibitory role of insulin. Both experimental $[11,12]$ and in vivo [13] studies have demonstrated that insulin inhibits VLDL apoB secretion from the liver in the normal insulin sensitive state. However, whether hepatic secretion of this apolipoprotein is increased in the insulin resistant state of NIDDM remains unresolved [14]. Hitherto, results of studies examining VLDL apoB secretion in NIDDM have been conflicting [15-18], possibly due to small sample size and differences in the study protocols or patient's characteristics. In addition, these studies used radioisotopic techniques which may introduce methodological difficulties associated with exogenous labelling of VLDL apoB $[19,20]$. Stable isotope methods using gas-chromatography massspectrometry (GCMS) are a relatively new approach for determining the kinetics of apoB metabolism [21] and may overcome some of the potential drawbacks associated with radioactive techniques.

GCMS may also be used to measure plasma mevalonic acid (MVA) concentration [22], a measure of in vivo cholesterol synthesis [23]. Studies in rat liver slices [24] and more recently in vivo [25-27] have demonstrated that cholesterol biosynthesis regulates VLDL apoB secretion. In addition, studies of Hep G2 cells have shown that in response to a fatty acid challenge, apoB secretion was increased as a result of enhanced cholesterol synthesis [28]. In vivo work has also shown that increased fatty acid supply to the liver following feeding stimulates VLDL apoB secretion [29]. Since there is increased fatty acid supply to the liver in NIDDM [30], it is possible that the effects of insulin resistance on hepatic secretion of apoB are mediated through increased intrahepatic cholesterol synthesis.

The main aim of this study was to employ a stable isotope technique to test the hypothesis that in NIDDM, hepatic secretion of VLDL apoB is increased. A secondary aim was to explore the associations between hepatic VLDL apoB secretion and plasma MVA, insulin and C-peptide concentrations.

\section{Subjects and methods}

Subjects. Six patients with NIDDM (four males, two females) who were attending the diabetic clinic volunteered for the study. Diabetes was diagnosed according to the World Health Organisation criteria and had been present for a minimum of 2 years. All the patients were treated with a modified diet ( $45 \%$ carbohydrate, $35 \%$ fat, $20 \%$ protein) alone and had a glycated haemoglobin less than $10.5 \%$. Six non-diabetic subjects matched for age and sex were also studied. They had been consuming a weight-maintenance (isocaloric) diet prior to the study. The subjects' clinical and biochemical characteristics are shown in Tables 1 and 2. None of the subjects had a primary lipid disorder, proteinuria, hypothyroidism, abnormal liver enzymes or were taking drugs known to affect lipid metabolism. All subjects provided informed written consent and 
Table 2. Biochemical data of the diabetic and non-diabetic subjects

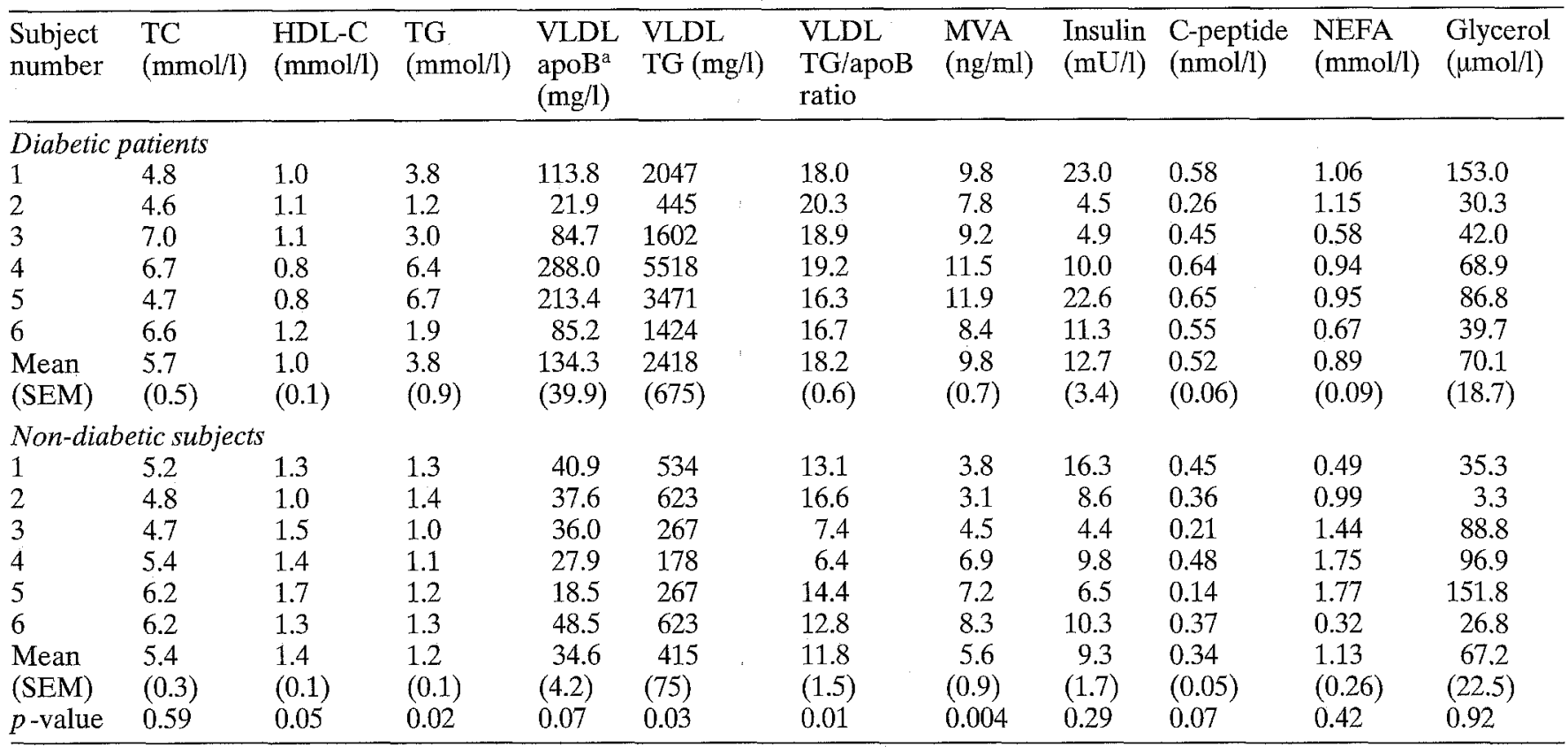

a Mean of three pooled samples (see Methods); there was no significant change in concentration during the studies

the study was approved by West Lambeth Health Authority Ethics Committee.

Experimental protocol (Fig. 1). All subjects were admitted to a metabolic ward at 08.00 hours after a 12 -h fast. They were studied in a semi-recumbent position and allowed to consume only water. An indwelling cannula was placed in a superficial vein of each antecubital fossa at the beginning of the study. $1{ }^{13} \mathrm{C}$ leucine (Tracer Technologies, Somerville, Mass., USA, $15 \mathrm{mg}$ / $\mathrm{ml},{ }^{13} \mathrm{C}$ enrichment $\left.99 \%\right)$, was administered as a primed (1 $\mathrm{mg} / \mathrm{kg})$, constant $\left(1 \mathrm{mg} \cdot \mathrm{kg}^{-1} \cdot \mathrm{h}^{-1}\right)$ infusion via the right cannula for $8 \mathrm{~h}$. Blood samples were collected from the left cannula into $10 \mathrm{ml}$ tri-potassium EDTA $(0.34 \mathrm{~mol} / 1)$ at baseline and at $30-\mathrm{min}$ intervals during the study. Blood samples $(5 \mathrm{ml})$ were collected into lithium heparin ( 15 units $/ \mathrm{ml}$ blood) at baseline and at 60 -min intervals to determine ${ }^{13} \mathrm{C}$ enrichment of plasma $\alpha$-ketoisocaproic acid $(\alpha-\mathrm{KIC})$, the deamination product of leucine which provides a measure of intracellular leucine enrichment [31]. At the beginning of the study, $10 \mathrm{ml}$ blood was collected into an EDTA $(0.34 \mathrm{~mol} / 1)$ tube to measure plasma total cholesterol (TC), HDL cholesterol, triglycerides (TG), glucose, $\mathrm{HbA}_{1}$, insulin and MVA concentrations and apolipoprotein $\mathrm{E}$ phenotype. Also, $10 \mathrm{ml}$ of blood was collected into a plain tube to measure non-esterified fatty acids (NEFA) and glycerol concentrations and $2 \mathrm{ml}$ of blood was collected into an EDTA tube containing $100 \mu \mathrm{l}$ of trasylol to measure C-peptide concentration.

Isolation and measurement of isotopic enrichment of VLDL apoB. The methods have been fully described elsewhere [32] and are summarised below. All EDTA samples were initially stored at $4{ }^{\circ} \mathrm{C}$ and analysed within $24 \mathrm{~h}$ of collection. A 2-ml aliquot of plasma was overlayered with $3 \mathrm{ml}$ of sodium chloride density solution $(\mathrm{d}=1.006 \mathrm{~kg} / \mathrm{l})$ and ultracentrifuged for $16 \mathrm{~h}$ at $147,000 \mathrm{~g}$. The supernatant containing VLDL was aspirated after separation from the infranatant by tube-slicing. ApoB within the VLDL fraction was precipitated by the tetramethylurea method, a technique that is highly specific for isolating apo $\mathrm{B}-100(>97 \%)[33,34]$. The precipitate was then delipidated, dried under oxygen-free nitrogen and then hydrolysed with $6 \mathrm{~mol} / 1$ hydrochloric acid for $24 \mathrm{~h}$ at $115^{\circ} \mathrm{C}$. After reconstitution in $50 \%$ acetic acid, the amino acids were eluted by cation-exchange chromatography using $2 \mathrm{ml}$ of $3 \mathrm{~mol} / 1$ ammonia. The eluted amino acids were lyophilised and stored at $-20^{\circ} \mathrm{C}$ until derivatisation. The samples were derivatised by the addition of $100 \mu \mathrm{l}$ acetonitrile and $100 \mu \mathrm{l} \mathrm{N}$-methyl-N-(tert-butyldimethylsilyl)-trifluoroacetamide to form the bis (tert-butyldimethylsilyl) derivative. Excess reagent was removed and the derivative reconstituted in $200 \mu \mathrm{l}$ decane for. GCMS analysis. Isotopic enrichment was determined by selected ion monitoring at $\mathrm{m} / \mathrm{z}$ of 303 and 302 using a Gas Chromatograph-Mass Spectrometer (VG Biotech TRIO-2, VG Biotech Ltd., Altringham, Cheshire, UK), employing electron-impact ionisation. ${ }^{13} \mathrm{C} /{ }^{12} \mathrm{C}$ leucine area ratios were corrected for the standard curve of observed vs expected isotopic enrichment of stock solutions of ${ }^{12} \mathrm{C}$ and ${ }^{13} \mathrm{C}$ leucine $(10 \mu \mathrm{g} /$ $\mathrm{ml}$ ) prepared for GCMS analysis as described above.

Plasma samples of $\alpha$-KIC were stored at $-70^{\circ} \mathrm{C}$ prior to extraction and on thawing were deproteinised using ethyl alcohol. After drying the supernatant and adding 1,2 phenylenediamine and hydrochloric acid, the keto-acids were extracted with ethyl acetate and dried over sodium sulphate. The dried residue was derivatised with $100 \mu \mathrm{l}$ of pyridine and $50 \mu \mathrm{l}$ of NO-bis (trimethylsilyl) trifluoroacetamide and $1 \%$ trimethylchlorosilane, and heated at $120^{\circ} \mathrm{C}$ for $45 \mathrm{~min}$ to form the quinoxalinol-tri-methyl silyl derivative. The sample was then prepared for GCMS analysis as for leucine. Isotopic enrichment was determined by selected ion monitoring at m/z 233 and 232 (GCMS analysis: Hewlett Packard 5890A, Bracknell, Herts., UK) using electron impact ionisation. Leucine and $\alpha$-KIC enrichment were calculated using the formula [35]:

$$
\text { Enrichment }(E)=\left[\frac{R_{t}}{R_{t}+1}-\frac{R_{0}}{R_{0}+1}\right] \times 100
$$

where $R t$ is the ${ }^{13} \mathrm{C}^{12} \mathrm{C}$ ratio at time $t$ and $\mathrm{R}_{0}$ is ${ }^{13} \mathrm{C}^{12} \mathrm{C}$ ratio at baseline prior to the infusion of $1-{ }^{13} \mathrm{Cleucine}$. Analytical precision of the method $(\mathrm{CV})$, assessed by taking replicate samples $(\times 5)$ at two time points in six of the studies, was less than $8 \%$ for isotopic enrichment $(\mathrm{E})$ of leucine and $\alpha-\mathrm{KIC}$. 


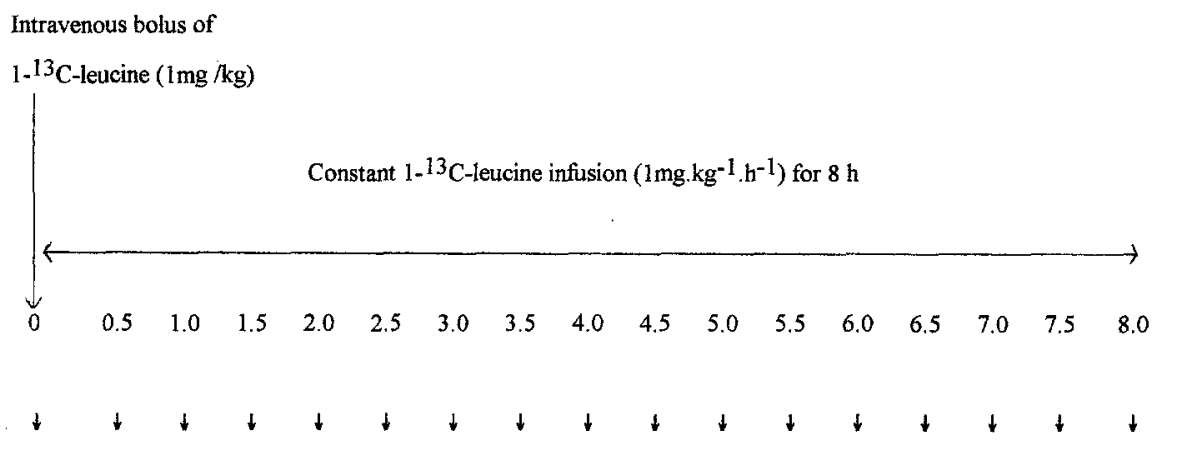

Fig. 1. Experimental protocol for determining hepatic VLDL apoB secretion rates using a primed, constant infusion of $1-{ }^{13}$ C-leucine

Blood sampling time points

Quantification of VLDL apoB and other analytes. VLDL was pooled from three successive hourly samples and VLDL apoB concentration was determined in each pooled sample using a modified Lowry method, as described previously [36]. The mean concentration of apoB in the three pooled VLDL samples per study was taken for purposes of calculating VLDL apoB secretion rate. Plasma TC and TG concentrations were measured by an enzymatic method (Boehringer Mannheim, Mannheim, Germany) using a Cobas-centrifugal analyser (Roche, Welwyn Garden City, Herts., UK). HDL cholesterol was separated by precipitation of apoB containing proteins with dextran sulphate/magnesium chloride and measured enzymatically. Plasma glucose was measured by a glucose oxidase technique (Yellow Springs 23 AM glucose analyser, Yellow Springs, Ohio, USA). $\mathrm{HbA}_{1}$ was measured by a high-performance liquid-chromatography method (interassay $\mathrm{CV}$ $8 \%$ ). Plasma immunoreactive insulin and C-peptide concentrations were measured in duplicate by double antibody radioimmunoassay techniques, interassay $\mathrm{CV} 6 \%$ and $5 \%$, respectively. Plasma NEFA and glycerol concentrations were measured by an enzymatic method using commercially available kits (NEFA: Randox Laboratory, Crumlin, Co. Antrim, N. Ireland, UK), interassay CV 3.6\%; (glycerol: Wako Laboratory, Neuss, Germany), interassay CV 3.2\%. Plasma MVA concentration was measured by capillary gas chromatography-electron capture mass spectrometry using a modified version [37] of the method described by Scoppola et al. [22], (Sigma, Poole, Dorset, UK and DB5 capillary GC column, $30 \mathrm{~m}$, Jones Chromatography, Mid-Glamorgan, UK), interassay CV $6.7 \%$. Apolipoprotein E phenotype was determined by isoelectric focusing [38].

Calculation of VLDL apoB secretion rate. The fractional secretion rate (FSR) of VLDL apoB (pools/day) was determined by fitting a monoexponential function to the enrichment data, [35]:

$$
Z(t)=F\left(1-e^{-k(t-d)}\right)
$$

where $\mathrm{F}$ is the precursor enrichment, $\mathrm{d}$ is the intrahepatic delay time, $k$ is the FSR of VLDL apoB and $Z(t)$ is the tracer:tracee mass ratio at time $t$ calculated as, [35]:

$$
[\mathrm{E}(\mathrm{t}) /(\mathrm{E}(\mathrm{I})-\mathrm{E}(\mathrm{t})]
$$

where $E(I)$ is the isotopic enrichment of the infusate. The Fig. P computer software package (Fig. P Software Corporation, Durham, N. C., US) was used to fit the monoexponential function. Initial estimates of the intrahepatic delay time and FSR were derived from the plot of $\mathrm{Z}(\mathrm{t})$ of VLDL apoB vs time data. Precursor enrichment (F) was estimated as the plateau isotopic enrichment from $\mathrm{Z}(\mathrm{t})$ of $\alpha-\mathrm{KIC}$ vs time data [39]. The curve fit for each set of data was accepted after finding the minimum value for the standard error (SE) of the estimated parameter $(\mathrm{P})$ expressed as a percentage of $\mathrm{P}$. Mean values of $[\mathrm{SE} / \mathrm{P} \times 100]$ for accepted curve fits were less than $9 \%$ for $\mathrm{F}$ and $\mathrm{d}$, and less than $16 \%$ for $\mathrm{k}$.

The absolute secretion rate (ASR) of VLDL apoB was calculated as the product of FSR and pool size. Pool size was determined as the product of plasma volume and VLDL apoB concentration. The plasma volume was measured at the midpoint of each study by a standard isotopic dilution technique using ${ }^{125} \mathrm{I}$ albumin [40].

\section{Statistical analysis}

Skewed variables (plasma and VLDL TG concentration, VLDL apoB concentration, pool size and ASR) were examined after $\log$ transformation. Since patients within each group were individually matched, Student's paired $t$-test was used to compare clinical, biochemical and kinetic characteristics as decribed by Altman [41]. Associations between VLDL apoB ASR and other variables were examined using simple linear regression methods. Variables that were significantly associated with apoB secretion rates $(p<0.05)$ following univariate analysis were then entered into multiple linear regression analysis in order to assess their relative association with VLDL apoB ASR.

\section{Results}

Table 1 shows that the patients and non-diabetic subjects were well matched for age, weight and sex. The diabetic patients had significantly higher plasma glucose, $\mathrm{HbA}_{1}$, TG, MVA concentrations, VLDL TG concentration and VLDL TG/apoB ratio than the non-diabetic subjects (Tables 1,2). Figure 2 demonstrates that steady-state isotopic enrichment of VLDL apoB was reached more rapidly in the nondiabetic subjects compared with the diabetic patients; in both groups, there was no significant difference between the isotopic enrichment of VLDL apoB and $\alpha$-KIC measured at 420 and 480 min. $\mathrm{He}-$ 

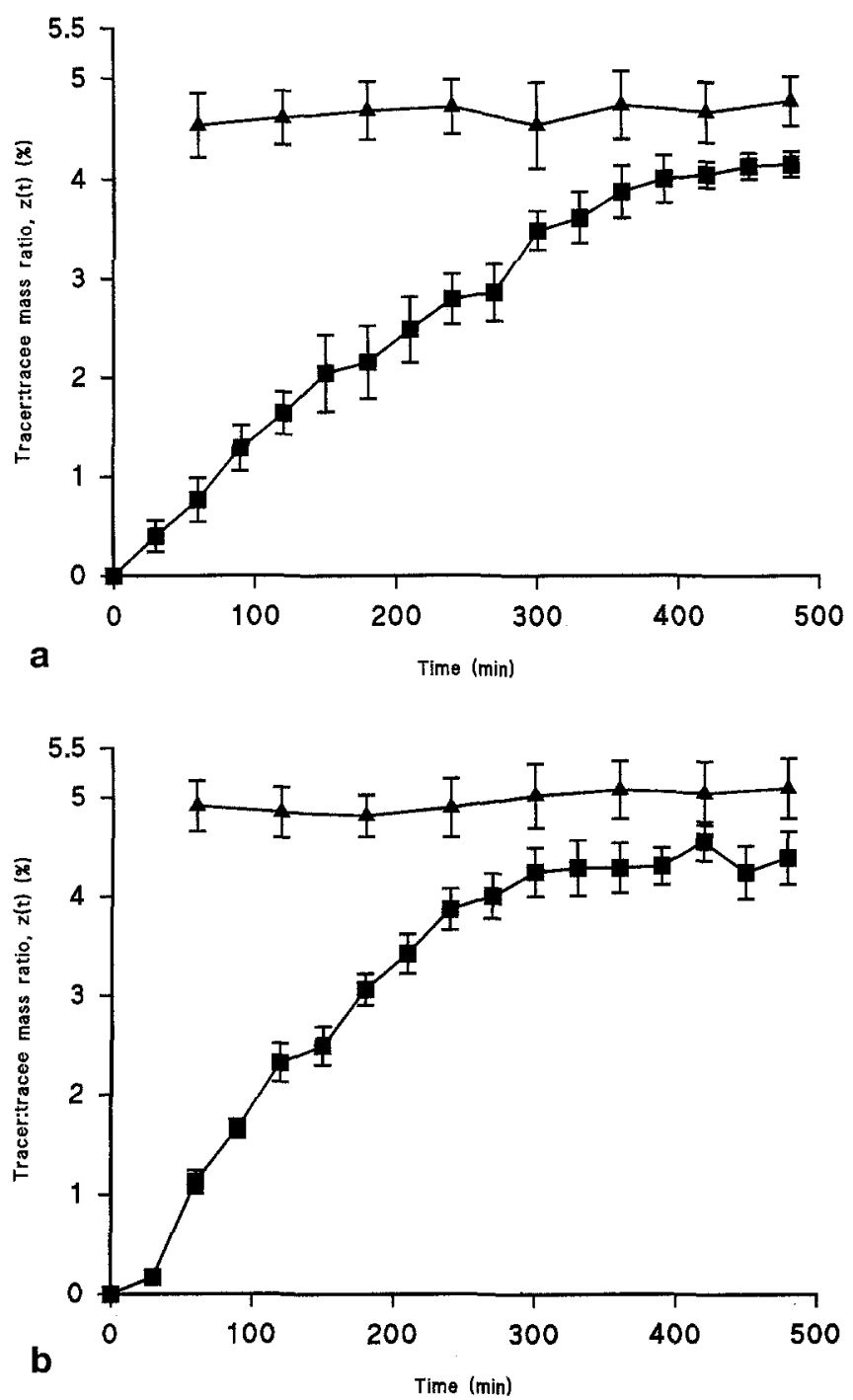

Fig. 2. (a, b) Tracer: tracee mass ratio of ${ }^{13} \mathrm{C}$ in VLDL apolipoprotein B-100 ( $\mathbf{0}$ ) and plasma $\alpha$-ketoisocaproic acid ( $\boldsymbol{\Delta}$ ). (a) Diabetic group, (b) non-diabetic group (mean \pm SEM)

patic VLDL apoB secretion rate, expressed as $\mathrm{mg} /$ day or $\mathrm{mg} \cdot \mathrm{kg}^{-1} \cdot$ day $^{-1}$ was significantly higher in the diabetic group compared with the non-diabetic group $(p<0.05)$ (Table 3$)$. The fractional catabolic rate (equivalent to fractional secretion rate at steady state) was not significantly different between the two groups (Table 3 ).

Univariate regression analysis showed a positive correlation between log VLDL apoB secretion rate $(\mathrm{mg} /$ day) and fasting C-peptide $(r=0.84, p=0.04)$ and MVA $(r=0.83, p<0.05)$ concentrations in the diabetic patients (Fig. 3); consistent with a significant positive association between plasma $\mathrm{C}$-peptide and MVA concentrations $(r=0.82, p<0.05)$ in this group. The association between VLDL apoB ASR and TG and VLDL TG almost reached conventional statistical sigificance $(p=0.06)$ in the diabetic patients. There was no significant association between these variables in the non-diabetic group. In addi-
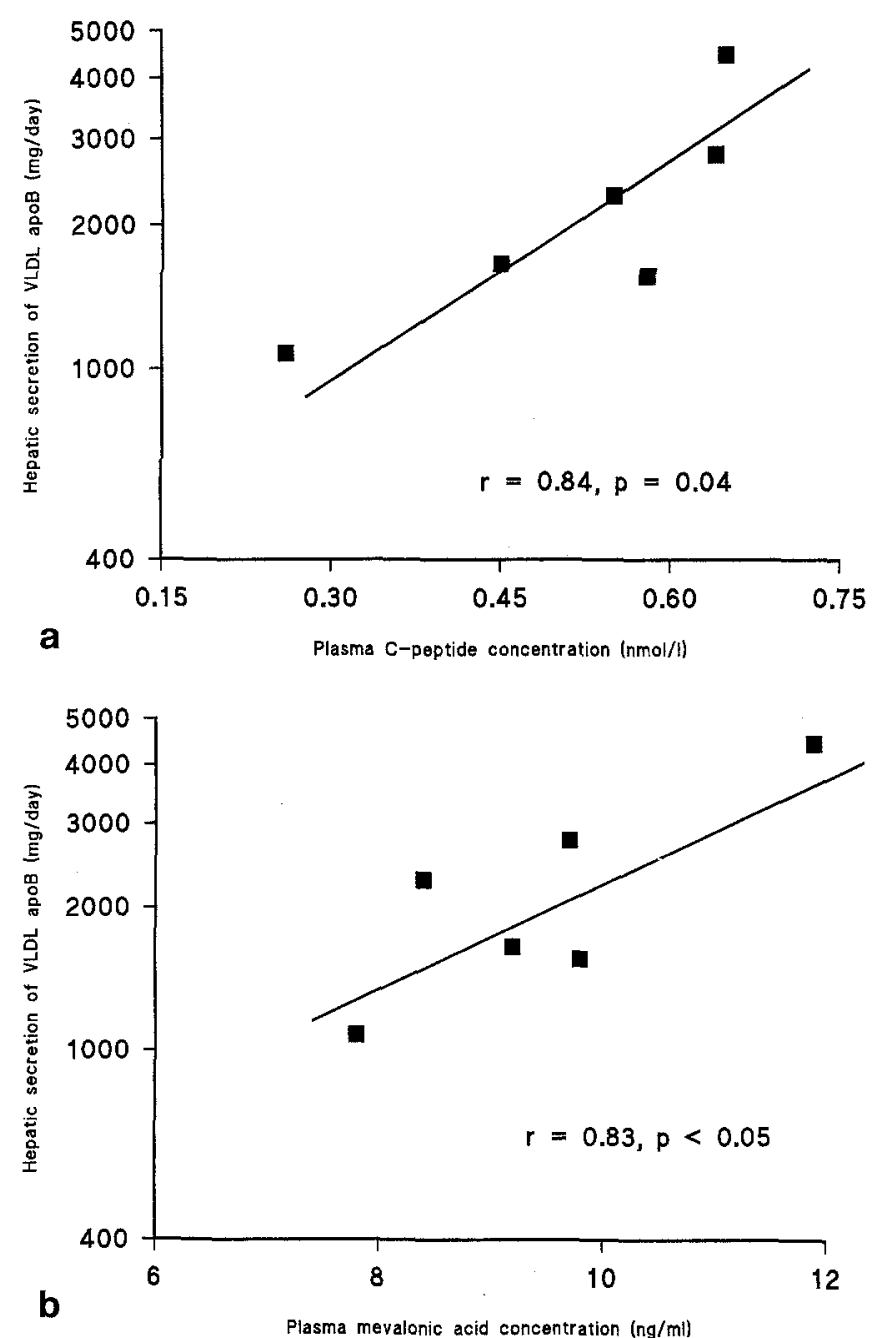

Fig. 3. (a, b) Association between the hepatic secretion of VLDL apolipoprotein B-100 and (a) plasma C-peptide concentration and (b) plasma MVA concentration in the diabetic subjects

tion, there was no significant association between VLDL apoB ASR and age, weight, BMI, HbA $\mathrm{H}_{1}$, plasma glucose, TG, NEFA or glycerol concentrations in either group. Following multiple linear regression analysis, the association between VLDL apoB ASR and both C-peptide and MVA concentrations were no longer significant in the diabetic subjects ( $p=0.35$ and $p=0.26$, respectively).

\section{Discussion}

This is the first study using stable isotopes to demonstrate increased hepatic secretion of VLDL apoB in NIDDM patients. The study also suggests that increased secretion of apoB may be due to insulin resistance, consistent with our findings in obese subjects [42]. Our results show that enhanced cholesterol synthesis is a feature of insulin resistance and that it may play an important role in increasing hepatic secretion of apoB in NIDDM. 
Table 3. Kinetic data of the diabetic and non-diabetic subjects

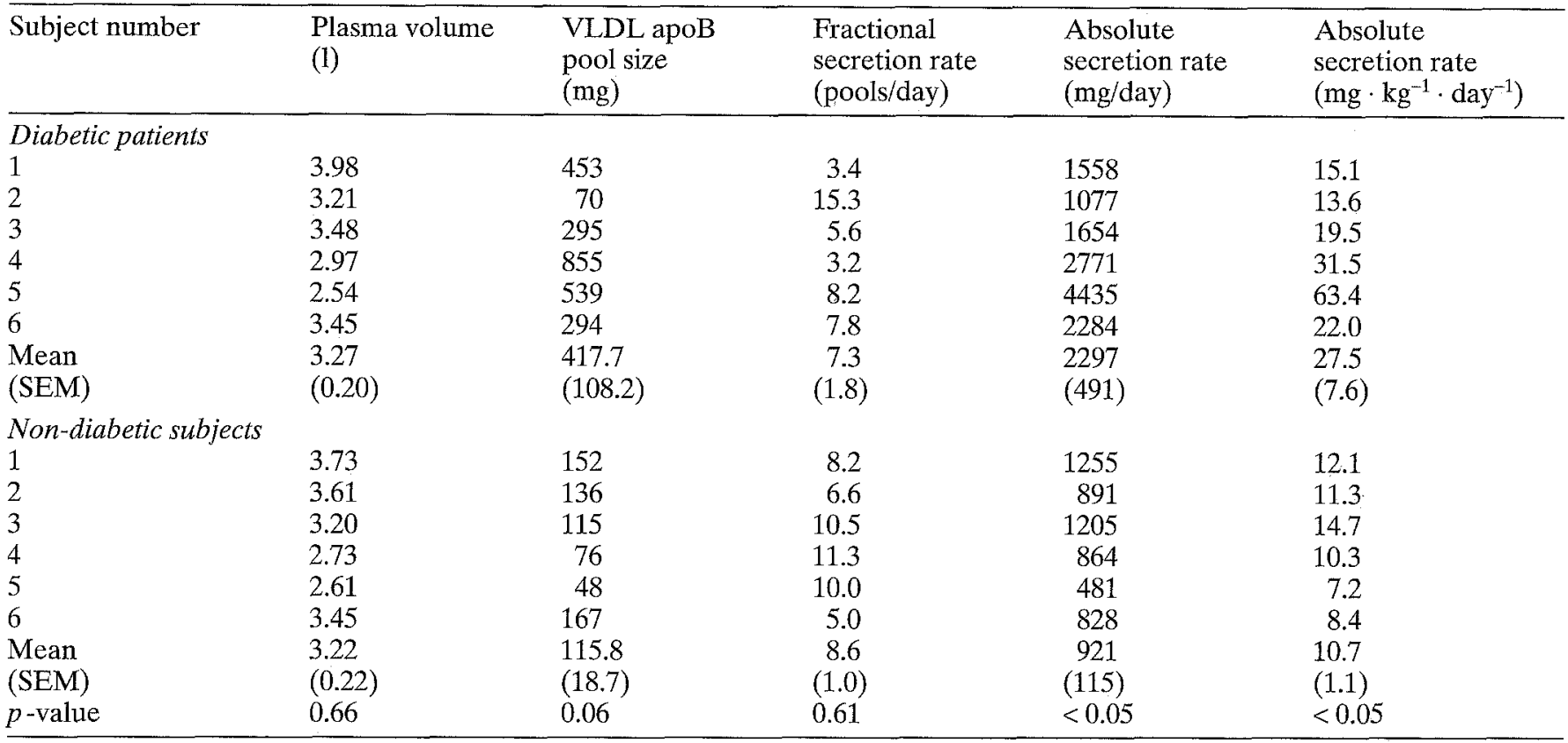

Hitherto, studies examining apoB secretion in NIDDM patients have used radioactive tracers and the findings have not been consistent. Kissebah et al. [15] showed that VLDL apoB secretion was increased in both normolipidaemic and hyperlipidaemic patients. In contrast, Taskinen et al. [16, 17] and Howard et al. [18] found normal VLDL apoB secretion rates in hyperlipidaemic diabetic patients. These studies exogenously labelled VLDL with

${ }^{131}$ iodine, a technique that may give rise to methodological errors: chemical modification during harvesting of VLDL that may alter its metabolism in vivo [19], non-uniform labelling of all subspecies of VLDL resulting in lower estimates of apoB transport [20] and VLDL apoB fractional secretion rates are not directly measured but inferred indirectly from fractional catabolic rates. In addition, the diabetic groups were not individually matched with control subjects for age, sex and weight which may affect interpretation of the findings. These potential methodological errors and differences in experimental protocols and patients' characteristics may explain the discrepancies in apoB secretion rates.

When interpreting our data, several assumptions were made. Monoexponential analysis incorporating a delay function was used to model the isotopic enrichment data, a method which has been used previously to examine VLDL apoB metabolism [21, 43]. The enrichment of plasma $\alpha-\mathrm{KIC}$ was used as a measure of intracellular leucine enrichment. This analysis assumes that steady-state isotopic enrichment of the precursor pool is constant at the beginning of the study. Although in practice, isotopic enrichment is zero at the beginning of each study, Figure 2 shows that steady-state enrichment of $\alpha$-KIC with ${ }^{13} \mathrm{C} \mathrm{oc}-$ curred rapidly, within $60 \mathrm{~min}$ of tracer infusion. Moreover, fractional secretion rates calculated by monoexponential analysis have been shown not to differ significantly from results using a more complex multicompartmental model in normolipidaemic subjects [21]. This analysis also assumes that plasma $\alpha$-KIC is in equilibrium with intrahepatic $\alpha-\mathrm{KIC}$ and that plasma $\alpha-\mathrm{KIC}$ (and hence intrahepatic $\alpha-\mathrm{KIC}$ ) reflects the enrichment of hepatic leucine amino acyl tRNA, the direct precursor of apoB. These two assumptions appear to be supported by experimental work in dogs demonstrating that there is equivalent enrichment of ${ }^{13} \mathrm{C}$ in leucine from hepatic tissue and plasma $\alpha$-KIC [44]. Moreover, in vivo studies confirm the isotopic enrichment of plasma $\alpha$-KIC and VLDL apoB to be highly correlated at steady state $[34,45]$.

In the non-diabetic state, acute hyperinsulinaemia decreases VLDL apoB secretion in experimental [11, $12]$ and in vivo [13] studies. Assuming that this effect of insulin may occur in the chronic hyperinsulinaemic state, this study suggests that in NIDDM the resistance to the inhibitory effect of insulin on apoB secretion causes increased secretion of this apolipoprotein by the liver. This is supported by the positive association between C-peptide concentration and VLDL apoB secretion rate in the diabetic subjects. Since raised C-peptide concentration is a relatively insensitive index of insulin resistance in NIDDM, this association may have been even stronger had we used glucose disposal rates during an insulin clamp procedure to assess insulin resistance [46]. We hypothesize that this enhanced secretion of apoB in NIDDM may be stimulated by increased intrahepatic cholesterol synthesis. Plasma MVA levels pro- 
vide a measure of in vivo cholesterol synthesis [23] and studies on rat liver slices [24], normolipidaemic adults [25] and patients with cholesterol ester storage disease $[26,27]$ have demonstrated that rates of cholesterol synthesis and VLDL apoB secretion are correlated. Increased hepatic cholesterol availability from an exogenous source may also increase apoB secretion, as evidenced by in vitro work [47] and our recent observation in patients with heterozygous familial hypercholesterolaemia [32]. In keeping with these findings, the present study demonstrated a positive association between plasma MVA concentration and VLDL apoB secretion in the diabetic group. Our data also showed that plasma MVA concentration was higher in the diabetic subjects which may be explained in part by differences in apoE phenotype; patients with the apo E2 allele have been shown to have higher rates of cholesterol synthesis than those patients with the E4 allele whilst cholesterol synthesis in apo E3E3 homozygotes lies between these two rates [48]. Since there was a positive association between plasma MVA and C-peptide concentrations, cholesterol synthesis may be increased also, as a result of insulin resistance. In contrast to our findings, others have reported that acute hyperinsulinaemia induced by using an insulin clamp in IDDM subjects [49], or consumption of a carbohydrate meal by IDDM and NIDDM subjects [50] stimulated cholesterol synthesis; they studied lymphocytes, however, which may not accurately reflect whole body cholesterol synthesis. In NIDDM, increased hepatic uptake of circulating NEFA due to insulin resistance [30] could have also increased VLDL apoB secretion, possibly by stimulating cholesterol synthesis. This is supported by studies in Hep G2 cells showing that in response to a fatty acid challenge, apoB secretion was increased as a result of enhanced cholesterol synthesis [28]. In addition, increased fatty acid supply to the liver following feeding stimulated VLDL apoB secretion in normolipidaemic adults [29]. The stimulatory effect of increased fatty acid availability has received further support recently from studies examining the addition of exogenous VLDL to Hep G2 cells in which fatty acid availability was the critical factor associated with increased apoB secretion [51]. A1though we did not find an association between plasma NEFA concentration and apoB secretion rates, others have shown an association between NEFA and apoB turnover rates [52].

In this study, we cross-sectionally examined a group of diabetic subjects with and without hyperlipidaemia. The results are in keeping with the findings of Kissebah et al. [15] demonstrating increased apoB secretion in both hypertriglyceridaemic and normotriglyceridaemic patients. However, studies using a larger sample size would be required in each group to fully establish the effects of NIDDM on apoB secretion independent of TG concentration. It is possi- ble that normal triglyceride concentrations are maintained in some diabetic patients by enhanced catabolism of VLDL apoB as observed in patients 2 and 6 , but our study suggests that in NIDDM, the predominant effect was on secretion of this apolipoprotein. This may reflect the good glycaemic control observed in our patients; poorly controlled diabetic patients have decreased lipoprotein lipase activity, consistent with decreased clearance of VLDL apoB [14]. Although the turnover of VLDL subspecies was not examined, we would have expected a high proportion of VLDL to be large and triglyceriderich as demonstrated in NIDDM patients studied elsewhere [16]. Further support for a predominance of triglyceride-rich VLDL is provided by increased TG/apoB ratios in VLDL of diabetic patients compared with non-diabetic subjects in the present and other studies $[17,18]$. Although we did not measure VLDL TG kinetics, several studies have shown that VLDL TG secretion is increased in NIDDM [1518]. Therefore, these observations would suggest that hepatic secretion of VLDL TG would have been increased to an even greater extent than that of VLDL apoB in our diabetic patients.

In conclusion, we suggest that in NIDDM insulin resistance increases cholesterol synthesis and that this may stimulate hepatic secretion of VLDL apoB. Further studies are required to confirm the association between VLDL apoB secretion and insulin resistance in NIDDM. For example, the insulin clamp technique at varying insulin concentrations could be used to examine the acute effect of insulin on apoB secretion. The effect of long-term insulin administration, as reported by others $[16,17]$, needs to be confirmed by examining apoB secretion in diabetic patients both before and after commencing insulin therapy. If the inhibitory effect of insulin on apoB secretion is clearly demonstrated, it would provide further evidence for an anti-atherogenic action of this hormone [53].

Acknowledgements. We wish to thank Ms. J. Kelly, Ms. N. Jackson and Mr. P. Lumb for their skilful technical assistance and Dr. G.W. Taylor and N.B. Rendell for their helpful advice. We also thank Mr. N. Taub for statistical advice. This study was funded in part by the British Diabetic Association and the Hordern Fund. Dr. M. Cummings is in receipt of a research grant from the Special Trustees for St. Thomas' Hospital.

\section{References}

1. Jarrett J (1990) Mortality in diabetes. Quart J Med 75: 413414

2. Merrin PK, Feher MD, Elkeles RS (1992) Diabetic macrovascular disease and serum lipids: is there a connection? Diabet Med 9: 9-14

3. Reaven GM (1988) Role of insulin resistance in human disease. Diabetes 37: 1595-1607 
4. Olefsky JM, Farquhar JW, Reaven GM (1974) Reappraisal of the role of insulin in hypertriglyceridaemia. Am J Med 57: $551-560$

5. Reaven GM, Greenfield MS (1981) Diabetic hypertriglyceridaemia. Evidence for three clinical syndromes. Diabetes 30: 66-75

6. Vogelberg KH, Gries FA, Moschinski D (1980) Hepatic production of very-low-density lipoprotein triglyceride. Dependence of portal substrate and insulin concentration. Horm Metab Res 12: 688-694

7. Pietri AO, Dunn FL, Grundy SM, Raskin P (1983) The effect of continuous subcutaneous insulin infusion on verylow-density lipoprotein triglyceride metabolism in type 1 diabetes mellitus. Diabetes 32: 75-81

8. Gibbons GF (1986) Hyperlipidaemia of diabetes. Clin Sci 171: $477-486$

9. Gibbons GF (1990) Assembly and secretion of hepatic very-low-density lipoprotein. Biochem J 268: 1-13

10. Ginsberg HN (1987) Very low density lipoprotein metabolism in diabetes mellitus. Diabetes/Metab Rev 3: 571-589

11. Sparks JD, Sparks CE (1990) Insulin modulation of hepatic synthesis and secretion of apolipoprotein B by rat hepatocytes. J Biol Chem 265: 8854-8862

12. Jackson TK, Salhanick AI, Elovson J, Deichman ML, Amatruda JM (1990) Insulin regulates apolipoprotein turnover and phosphorylation in rat hepatocytes. J Clin Invest 86: 1746-1751

13. Lewis GF, Uffelman KD, Szeto LW, Steiner G (1993) Effects of acute hyperinsulinaemia on VLDL triglyceride and VLDL apoB production in normal weight and obese individuals. Diabetes 42: 833-842

14. Howard BV (1987) Lipoprotein metabolism in diabetes mellitus. J Lipid Res 28: 613-628

15. Kissebah AH, Alfarsi S, Evans DJ, Adams PW (1982) Integrated regulation of very low density lipoprotein triglyceride and apolipoprotein-B kinetics in non-insulin dependent diabetes mellitus. Diabetes 31: 217-225

16. Taskinen M-R, Packard CJ, Shepherd J (1990) Effect of insulin therapy on metabolic fate of apolipoprotein B-containing lipoproteins in NIDDM. Diabetes 39: 1017-1027

17. Taskinen M-R, Beltz WF, Harper I et al. (1986) Effects of NIDDM on very-low-density lipoprotein triglyceride and apolipoprotein B metabolism. Studies before and after sulfonylurea therapy. Diabetes 35: 1268-1277

18. Howard BV, Abbott WGH, Beltz WF et al. (1987) Integrated study of low-density lipoprotein metabolism and very-low-density-lipoprotein metabolism in non-insulindependent diabetes. Metabolism 36: 870-877

19. Beltz WF, Kesaniemi YA, Miller NH, Fisher WR, Grundy SM, Zech LA (1990) Studies on the metabolism of apolipoprotein B in hypertriglyceridaemic subjects using simultaneous administration of tritiated leucine and radioiodinated very low density lipoprotein. J Lipid Res 31: 361-374

20. Ramakrishnan R, Arad Y, Wong S, Ginsberg HN (1990) Nonuniform radiolabelling of VLDL apolipoprotein B: implications for the analysis of studies of the kinetics of the metabolism of lipoproteins containing apolipoprotein B. J Lipid Res 31: 1031-1042

21. Parhofer KF, Barrett PHR, Bier DM, Schonfeld G (1991) Determination of kinetic parameters of apolipoprotein $B$ metabolism using amino acids labeled with stable isotopes J Lipid Res 32: 1311-1323

22. Scoppola A, Maher VMG, Thompson GR, Rendell NB, Taylor GW (1991) Quantitation of plasma mevalonic acid using gas chromatography-electron capture mass spectrometry. J Lipid Res 32: 1057-1060
23. Parker TS, Mcnamara DJ, Brown CD et al. (1984) Plasma mevalonate as a measure of cholesterol biosynthesis in man. J Clin Invest 74: 795-804

24. Khan BK, Wilcox HG, Heimberg M (1989) Cholesterol is required for secretion of very-low-density lipoprotein by rat liver. Biochem J 259: 807-816

25. Naoumova RP, Cummings MH, Watts GF, Thompson GR (1994) Direct correlation between in vivo cholesterol synthesis and hepatic secretion of apolipoprotein B-100 in normolipidaemic subjects. Atherosclerosis 109: 102-103 (Abstract)

26. Ginsberg HN, Le N-A, Short M, Ramakrishnan R, Desnick RJ (1987) Suppression of apolipoprotein B production during treatment of cholesteryl ester storage disease with lovastatin. J Clin Invest 80: 1692-1697

27. Cummings MH, Watts GF (1995) Increased hepatic secretion of very-low-density lipoprotein apolipoprotein B-100 in cholesterol ester storage disease. Clin Chem 41: 111-114

28. Cianflone K, Yasruel Z, Rodriguez MA, Vas D, Sniderman AD (1990) Regulation of apoB secretion from HepG2 cells: evidence for a critical role for cholesteryl ester synthesis in the response to a fatty acid challenge. J Lipid Res 31: $2045-2054$

29. Cohn JS, Wagner DA, Cohn SD, Millar JS, Schaefer EJ (1990) Measurement of very low density and low density lipoprotein apolipoprotein (apo) B-100 and high density lipoprotein apo A-1 production in human subjects using deuterated leucine. Effects of feeding and fasting. J Clin Invest 85 : 804-811

30. Bogardus C, Lillioja S, Howard BV, Reaven GM, Mott D (1984) Relationships between insulin secretion, insulin action, and fasting plasma glucose concentration in non-diabetic and non insulin dependent diabetic subjects. J Clin Invest 74: $1238-1246$

31. Matthews D E, Schwartz HP, Yand RD, Motil KJ, Young VR, Bier DM (1982) Relationship of plasma leucine and alpha-ketoisocaproate during a $\mathbf{L}-\left[1-{ }^{13} \mathrm{C}\right]$ leucine infusion in man: a method for measuring human intracellular leucine tracer enrichment. Metabolism 31: 1105-1112

32. Cummings MH, Watts GF, Umpleby M, Hennessy TR, Quiney JR, Sonksen PH (1995) Increased hepatic secretion of very-low-density lipoprotein B-100 in heterozygous familial hypercholesterolaemia: a stable isotope study. Atherosclerosis 113: 79-89

33. Kane JP, Sata T, Hamilton RL (1975) Apoprotein composition of very low density lipoproteins of human serum. J Clin Invest 56: 1622-1634

34. Venkatesan S, Cullen P, Halliday D, Scott J (1993) Stable isotopes show a direct relation between VLDL apoB overproduction and serum triglyceride levels and indicate a metabolically and biochemically coherent basis for familial combined hyperlipidaemia. Arteriosclerosis Thrombosis 13: $1110-1118$

35. Cobelli C, Toffolo G, Foster DM (1992) Tracer-to-tracee ratio for analysis of stable isotope tracer data: link with radioactive kinetic formalism. Am J Physiol 262:E968-E975

36. Cummings MH, Watts GF, Lumb PJ, Slavin BM (1994) Comparison of immunoturbidimetric and Lowry methods for measuring concentration of very low density lipoprotein apolipoprotein B-100 in plasma. J Clin Path 47: 176178

37. Pfohl M, Naoumova RP, Klass C et al. (1994) Acute and chronic effects on cholesterol biosynthesis of LDL-apheresis with or without concomitant $\mathrm{HMG}-\mathrm{CoA}$ reductase inhibitor therapy. J Lipid Res 35(11):1946-1955

38. Davignon J, Gregg RE, Sing SF (1988) Apolipoprotein E polymorphisms and atherosclerosis. Arteriosclerosis 8: 1-21 
39. Foster DM, Barrett PHR, Toffolo G, Beltz WF, Cobelli C (1993) Estimating the fractional synthetic rate of plasma apolipoproteins and lipids from stable isotope data. $\mathrm{J} \mathrm{Li}$ pid Res 34: 2193-2205

40. ICSH (1980) Recommended methods of measurement of red-cell and plasma volume. J Nuclear Med 21: 793-812

41. Altman DG (1992) Comparing groups - continuous data. In: Altman (ed) Practical statistics for medical research. Chapman and Hall, London Glasgow New York Tokyo Melbourne Madras, pp179-228

42. Cummings MH, Watts GF, Pal C et al. (1995) Increased hepatic secretion of very-low-density-lipoprotein apolipoprotein-B100 in obesity: a stable isotope study. Clin Sci 88: $225-233$

43. Arends J, Bier DM, Schafer G et al. (1993) No evidence for feedback inhibition of hepatic apolipoprotein B (apoB) production after extracorporeal low density lipoprotein precipitation by $\left[1-{ }^{13} \mathrm{C}\right]$ leucine infusion in normal volun teers. Eur J Clin Invest 23: 602-614

44. Layman DK, Wolfe RR (1987) Sample site selection for tracer studies applying a unidirectional circulatory approach. Am J Physiol 253:E173-E178

45. Pacy PJ, Venkatesan S, Bannister P, Millward DJ, Halliday $D$ (1991) Is plasma ${ }^{13} \mathrm{C}$ - $\alpha$-ketoisocaproic acid representative of the hepatic precursor pool? Clin Sci 80: 20 (Abstract)
46. DeFronzo RA, Tobin JD, Andres R (1979) Glucose clamp technique: a method for quantifying insulin secretion and resistance. Am J Physiol 237:E214-E223

47. Dashti N (1992) The effect of low-density-lipoprotein cholesterol and 25-hydroxy cholesterol in apolipoprotein B gene expression in Hep G2 gene cells. J Biol Chem 267: $7160-7169$

48. Kesaniemi YA, Ehnholm C, Miettinen TA (1987) Intestinal cholesterol absorption efficiency in man is related to apoprotein E phenotype. J Clin Invest 80: 578-581

49. Tomkin GH, Owens D (1991) Abnormalities of cholesterol metabolism in diabetes. Proc Nutr Soc 50: 583-589

50. Stinson JC, Owens D, Collins P, Johnson A, Tomkin GH (1993) Hyperinsulinaemia is associated with stimulation of cholesterol synthesis in both type 1 and type 2 diabetes. Diabet Med 10: 412-419

51. Wu X, Sakata N, Dixon J, Ginsberg HN (1994) Exogenous VLDL stimulates apolipoprotein B secretion from HepG2 cells by both pre- and post-translational mechanisms. J Lipid Res 35: 1200-1210

52. Kissebah AH, Alfarsi S, Adams PW, Wynn V (1976) Role of insulin resistance in adipose tissue and liver in the pathogenesis of endogenous hypertriglyceridaemia in man. Diabetologia 12: 563-571

53. Durrington PN (1992) Is insulin atherogenic? Diabet Med 9: $597-600$ 